\title{
A Review of Bio-Oil Production through Microwave- Assisted Pyrolysis
}

\author{
Mauro Giorcelli ${ }^{1,2}$ (D), Oisik Das ${ }^{3}$, Gabriel Sas ${ }^{3}$, Michael Försth ${ }^{3}$ (D) and Mattia Bartoli ${ }^{2,4, *(D)}$ \\ 1 Italian Institute of Technology, Via Livorno 60, 10144 Torino, Italy 1, 10129 Turin, Italy; \\ mauro.giorcelli@polito.it \\ 2 Consorzio Interuniversitario Nazionale per la Scienza e Tecnologia dei Materiali (INSTM), Via G. Giusti 9, \\ 50121 Florence, Italy \\ 3 Structural and Fire Engineering Division, Department of Civil, Environmental and Natural Resources \\ Engineering, Luleå University of Technology, 97187 Luleå, Sweden; oisik.das@ltu.se (O.D.); \\ gabriel.sas@ltu.se (G.S.); michael.forsth@ltu.se (M.F.) \\ 4 Department of Applied Science and Technology, Politecnico di Torino, Corso Duca degli Abruzzi 24, \\ 10129 Torino, Italy \\ * Correspondence: mattia.bartoli@polito.it; Tel.: +39-011-094-326
}

Citation: Giorcelli, M.; Das, O.; Sas,

G.; Försth, M.; Bartoli, M. A Review of Bio-Oil Production through Microwave-Assisted Pyrolysis. Processes 2021, 9, 561. https:// doi.org/10.3390/pr9030561

Academic Editor:

Elsayed Elbeshbishy

Received: 29 January 2021

Accepted: 22 March 2021

Published: 23 March 2021

Publisher's Note: MDPI stays neutral with regard to jurisdictional claims in published maps and institutional affiliations.

Copyright: (c) 2021 by the authors. Licensee MDPI, Basel, Switzerland. This article is an open access article distributed under the terms and conditions of the Creative Commons Attribution (CC BY) license (https:// creativecommons.org/licenses/by/ $4.0 /)$.

\begin{abstract}
The issue of sustainability is a growing concern and has led to many environmentally friendly chemical productions through a great intensification of the use of biomass conversion processes. Thermal conversion of biomass is one of the most attractive tools currently used, and pyrolytic treatments represent the most flexible approach to biomass conversion. In this scenario, microwave-assisted pyrolysis could be a solid choice for the production of multi-chemical mixtures known as bio-oils. Bio-oils could represent a promising new source of high-value species ranging from bioactive chemicals to green solvents. In this review, we have summarized the most recent developments regarding bio-oil production through microwave-induced pyrolytic degradation of biomasses.
\end{abstract}

Keywords: pyrolysis; microwave; biomass; waste

\section{Introduction}

Since early last century, developments made by humans have significantly contributed to resource depletion [1]. The advancement of industrialization has required a great consumption of oil and its derivatives, leading to a rise in pollution [2]. Waste and end-life materials have both become an environmental threat and caused an unsustainable loss of resources. As an example of the consumption of resources, Qualman et al. [3] reported production of up to 400 million tons/y of plastics in 2017 together with a recycled amount of up to a maximum of $18 \mathrm{wt} . \%$. Waste-streams of unrecycled plastics are managed mainly through incineration and landfill with an increment of environmental stress [4]. Furthermore, fossil resources are limited, although they are supplemented by alternatives to traditional oil sources [5]. The use of biomass is a promising replacement for oil-derived chemicals due to their wide availability and ease of renewability [6,7]. The main drawback of this approach is due to the shift of all the current production from oil-based materials to biomass-derived ones. Replacing oil-based feedstock with biomass-derived ones is quite challenging due to two main issues: (i) high oxygen content and (ii) feedstock variability [6] An interesting solution to both problems could be represented by biomass thermochemical conversion through pyrolytic processes [8-14]. Pyrolysis is a high-temperature thermochemical treatment in an oxygen-free atmosphere [15] that induces the radical degradation of biomass and produces biochar, bio-oil, and gas [13]. Pyrolysis of biomass leads to the production of chemicals [14], including carbon [16,17], but some issues remain unsolved. The main drawback is represented by the complexity of bio-oil mixtures, leading to difficulties in isolating and purifying single products $[18,19]$. Nonetheless, several procedures have 
been developed to extract high-value products such as phenols [20,21]. Among various available heating solutions, technologies based on microwaves (MWs) have gained much interest [22]. At the lab scale, microwave-assisted pyrolysis (MAP) is a reliable approach to process a wide range of feedstocks [23].

MAP of biomasses produces promising bio-oils due to rapid and volumetric heating in a temperature range from 500 up to $700 \mathrm{~K}$ [24-26] without requiring feedstock milling, unlike conventional fast pyrolysis [27]. Moreover, the presence of water inside the feedstock could enhance the heating rate and mitigate the highest temperature reached during pyrolysis, avoiding advanced cracking degradation.

In this review, we report the main achievements in bio-oil production using several kinds of MAP set-up biomasses and provide an up-to-date reference point for the field.

\section{Brief Overview of MW Interaction with Materials}

MWs represent the range of electromagnetic radiation with frequencies ranging from $0.3 \mathrm{GHz}$ to $300 \mathrm{GHz}$ [28]. MWs interact with matter through (i) dipole reorientation or (ii) Maxwell-Wagner polarization and (iii) electric conduction.

The interaction between MWs and matter is dependent on the electrical properties of the material. Accordingly, materials can be classified as dielectric (i.e., water [29], silica [30], and alumina [31]) and conductive (i.e., salts [32], metals [33], and metal oxides [34]) Dielectric and conductive materials are heated by MWs with two different mechanisms. A dielectric material is heated by a fast spatial reorientation of dipoles instantly formed in its bulk. Conductive materials are heated by conduction loss due to the resistance produced by the electric flux originating in the movement of induced electrons under MW irradiation.

The main issue related to MAP is the poor ability of biomasses to absorb MW below a density power threshold of up to $108 \mathrm{~W} / \mathrm{m}^{3}$ [35] that is rarely reached by MAP units. This leads to the common practice of the addition of a MW absorber to biomasses prior to the MAP. Even if this procedure is very effective, it leads to difficulty in measuring temperature during the MAP, as described by Bartoli et al. [36].

\section{MAP of Lignocellulosic Biomasses}

Pyrolysis of lignocellulosic biomass proceeds through different steps controlled by temperature. Firstly, the moisture is released from the feedstock at a temperature of over $373 \mathrm{~K}$ with an increase in the surface area and improvement of the pore structure. Afterward, the three components of lignocellulosic biomass start the process of degradation at different temperatures with different reaction pathways. Pyrolysis of hemicellulose takes place from 470 and $570 \mathrm{~K}$, cellulose in the range from 620 to $670 \mathrm{~K}$, and lignin among 670 and $720 \mathrm{~K}$ [37].

The reactions occurring during the cracking of single lignocellulosic biomass constituents are very complex [37] and will be detailed in the next sections. It is noteworthy that the reactivity of each biomass component can be studied by itself due to negligible crossreactivity between sugar-based and lignin polymers. This phenomenon is appreciable only by monitoring highly reactive species such as levoglucosan, as reported by Zhang et al. [38]. The authors studied the reactivity of mixtures of cellulose/hemicellulose/lignin and native wood, showing only a depletion of levoglucosan considering native wood. The speculative hypothesis reported by the authors suggests that it was due to the covalent linkage between lignin and cellulose in biomasses. Generally, reactivities observed during classical pyrolysis are slightly different from those observed during MAP.

\subsection{MAP of Cellulose}

Cellulose is a structural wood component representing up to $40 \mathrm{wt} . \%$ its weight [39]. Cellulosic polymers chains are composed of $D$-glucose units bonded through $\beta-(1,4)$ glycosidic bonds with molecular weight from $1800 \mathrm{kDa}$ up to $4000 \mathrm{kDa}$ [40].

MAP of cellulose involves a reaction, as summarized in Figure 1, with several thermochemical cracking processes [41-43]. 


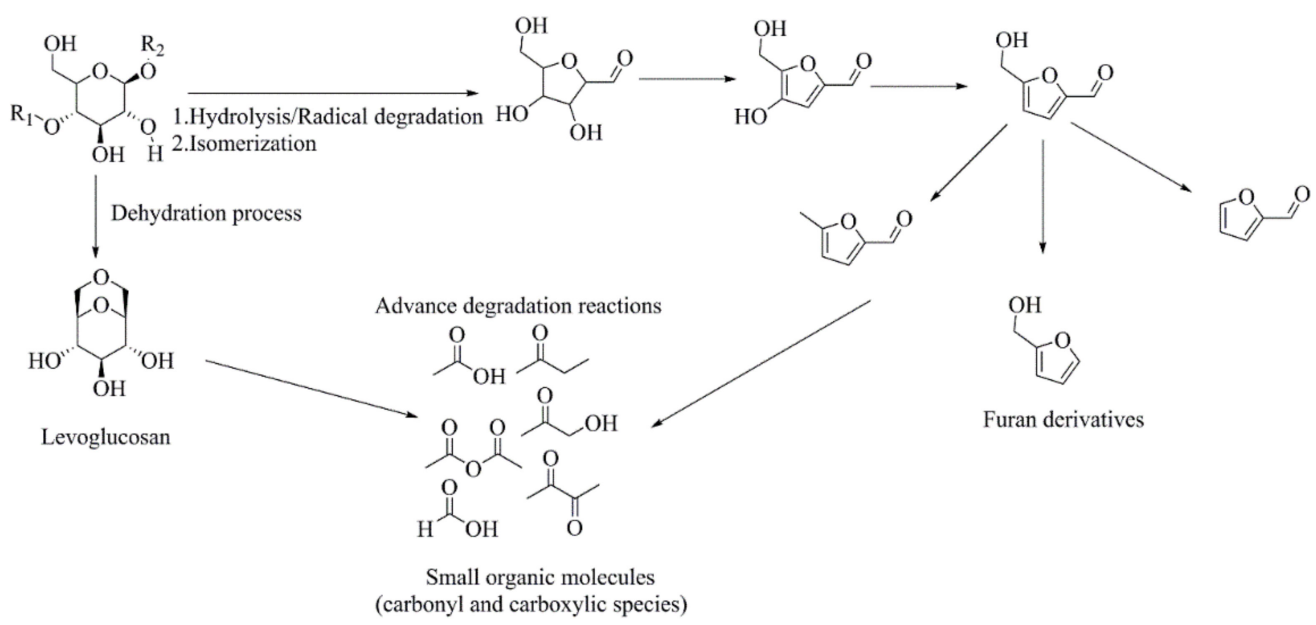

Figure 1. Main reactions occurring during cellulose microwave-assisted pyrolysis (MAP).

A possible degradation mechanism is represented by the direct dehydration process with the formation of anhydrosugars.

Miura et al. [44] described the cellulose MAP in a large multimode reactor achieving a levoglucosan yield of up to $2.6 \mathrm{wt}$.\% based on the mass of dry wood and other sugar derivatives (i.e., levoglucosenone, mannosan, galactosan, and xylosan). Alternatively, cellulose can be cracked through a radical degradation/isomerization producing a mixture of furans [45].

An additional degradation route was first reported by Bartoli et al. [26] (Figure 2) during pyrolysis of crystalline cellulose in a multimode batch reactor.

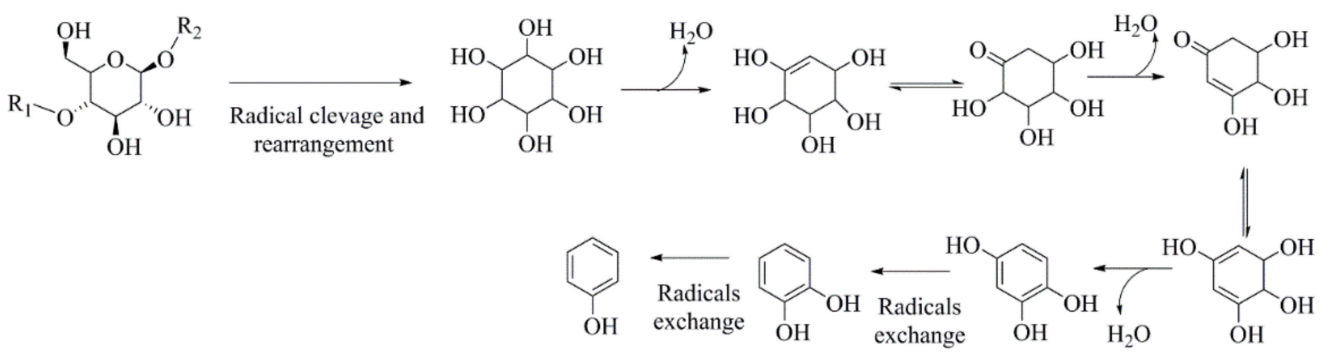

Figure 2. Chemical pathway of aromatics formation during MAP of cellulose as reported by Bartoli et al. [26].

The authors identified aromatic compounds and a reasonable polyalcohol precursor to explain the formation of phenol and phenolic compounds through a simple radical rearrangement and dehydration process.

Furthermore, Bartoli and co-workers reported the strong influence of a MW absorption additive that achieved gas production of $54 \mathrm{wt} . \%$ using carbon and biochar yield of up to $64.1 \mathrm{wt}$ \% by using $\mathrm{Al}_{2} \mathrm{O}_{3}$. The use of iron powder as a $\mathrm{MW}$ absorber induced a high bio-oil production of up to $38 \mathrm{wt}$ \%, but the quality of the liquid fraction was very poor with a high amount of water and acetic acid. This was probably due to the advanced cracking process induced by metallic susceptors. Additionally, by using graphite as a susceptor, levoglucosan was detected in a high concentration of up to $134 \mathrm{mg} / \mathrm{mL}$ together with small organic acids and acid derivatives (i.e., formic acid, acetic acid, and anhydride, 1-hydroxy2-propanone) and furans. Aromatics can also be obtained from catalytic MAP of cellulose, as reported by Wang et al. [46]. The authors increased the production of aromatics by using several metal-containing zeolites (iron-doped HZSM-5, nickel-doped HZSM-5, and iron-/nickel-doped HZSM-5), promoting the aromatization of sugars and anhydrosugars into phenolic compounds through a dehydration route. Contrary to conventional heating 
processes, MAP of cellulose can occur at lower temperature values, as reported by $\mathrm{Al}$ Shra'ah et al. [47]. The authors studied MAP of amorphous cellulose in a lab-scale modified organic synthesis unit operating at $455 \mathrm{~K}$. They achieved a bio-oil yield of up to $47 \mathrm{wt} . \%$ with a remarkable production of levoglucosan compared with traditional fast pyrolysis run at the temperature of $673 \mathrm{~K}$. Pristine cellulose can be easily replaced by cellulose wastestreams, as reported by Zhang et al. [48]. The authors used de-inking paper residues for $\mathrm{MAP}$, reaching temperatures lower than $675 \mathrm{~K}$ and achieving good bio-oils yields. Similarly, Undri et al. [49] processed cellulose-based multilayered packaging, producing two-phase bio-oils. The watery phase recovered was analogous to the product distribution produced by the conversion of cellulose through MAP.

\subsection{MAP of Hemicellulose}

MAP of hemicellulose is poorly described in literature due to its high cost and long purification process. Nonetheless, hemicellulose MAP has been studied by modeling through computational approaches evaluating the influence of temperature on gas fraction composition [50,51]. Hemicellulose cracking under pyrolytic conditions displayed a quite different product distribution compared to those achieved by processing cellulose [52] Patwardhan et al. [53] reported a degradative pathway where xylan degradation played the main role. The authors proposed a mechanism based on the direct conversion of xylan to xylose during the very early stages of the process. Li et al. [54] described an interesting pyrolytic conversion of hemicellulose by using a pressurized batch MW reactor without using any additional MW absorbers. The authors achieved an efficient pyrolytic conversion with a low water content bio-oil yield of up to $21 \mathrm{wt} . \%$. Bio-oils recovered lacked in anhydrosugars, but they were rich in aldehydes, phenolic derivatives, aromatic hydrocarbons, and functionalized furans that were quite different from the products of cellulose MAP.

\subsection{MAP of Lignin}

Lignin is a cross-linked biopolymer based on aromatic moieties bonded together by various carbon-carbon and carbon-oxygen bonds [55]. Lignin represents up to $30 \mathrm{wt} . \%$ of the total weight of wood, and it has a complex branched structure [56]. Nonetheless, it is accepted that lignin is produced by the condensation of three monomers named primary monolignols: $p$-coumaryl, coniferyl, and sinapyl alcohol. Lignin can be isolated as kraft, pure, or sulphonate derivatives recovered from [57] pulp and mills or bioethanolproductive platforms [58]. During pyrolysis, lignin undergoes several cracking reactions, as reported by several authors [59-61] and sketched in Figure 3.

Fan et al. [62] investigated MAP of lignin using various MW susceptors such as carbons (biochar, activated carbon) and silicon carbide ( $\mathrm{SiC}$ ). $\mathrm{SiC}$ promotes three separate heating stages correlated to the lignin degradative steps. The first one is represented by the radical breaking of the functionalities directly bonded to aromatic moieties producing low molecular weight complex structures occurring up to $473 \mathrm{~K}$. The next step involved the aromatic fragments radical rearrangement and additional degradation up to $673 \mathrm{~K}$. During the final stage, compounds produced during the early stages of lignin degradation underwent a self-condensation process until the completion of feedstock conversion. During this step, reactivity was driven by the combination of many parameters such as phenolic moieties amount and inorganic element concentrations in both lignin and MW absorbers [63]. The authors also reported that a high load of $\mathrm{SiC}$ facilitated the production of alkylated phenols. Carbon-based MW absorbers promoted a massive formation of syngas of up to $70 \mathrm{wt} . \%$. Elsewhere, Yerrayya et al. [64] used different carbon-based materials (activated carbon, charcoal, and graphite), improving the yield and selectivity of phenolic fraction in bio-oil produced by using a MW batch reactor and an organosolv lignin. They reported a direct relationship between the increment of MW absorbers and bio-oil production with an enhancement of up to $66 \mathrm{wt} . \%$ with selectivity to phenolic compounds of up to $90 \%$. MAP of kraft lignin was studied by Farag and co-workers [65] by 
comparing the yields and compositions of bio-oils with those of fast pyrolytic process. The authors proved that MAP induced a higher bio-oil yield, preserving at the same time the structure of the functionalized aromatic compounds. Additionally, several upgrades have been proposed for the improvement of bio-oils recovered from lignin MAP conversion. Duan et al. [66] reported MAP of lignin mixed with poly(propylene) to produce bio-oils with less amounts of oxygen. Similarly, Fan et al. [67] described a catalytic co-pyrolysis of lignin and low-density poly(ethylene) and cracking catalyst made with HZSM-5 and $\mathrm{MgO}$. Remarkably, the authors reported a significant increment of non-oxygenated aromatic species with the increment of poly(ethylene)/lignin ratio. This was due to the retro Diels-Alder reaction process as discussed by Undri et al. [68] for MAP of polyolefins. A similar behavior was observed by increasing the ratio of HZSM-5/MgO even if it led to an increment of alkylated phenol. The authors described an additional development of this procedure through an ex-situ catalytic upgrading of bio-oil vapors over HZSM-5 [69], reaching the best selectivity of alkylated phenolic compounds with a catalyst loading of up to $0.2 \mathrm{wt} . \%$. Another interesting approach was reported by Bartoli et al. [70] that performed MAP of kraft lignin under reduced pressure. The results reported suggest a different evolution of lignin cracking as shown in Figure 4.

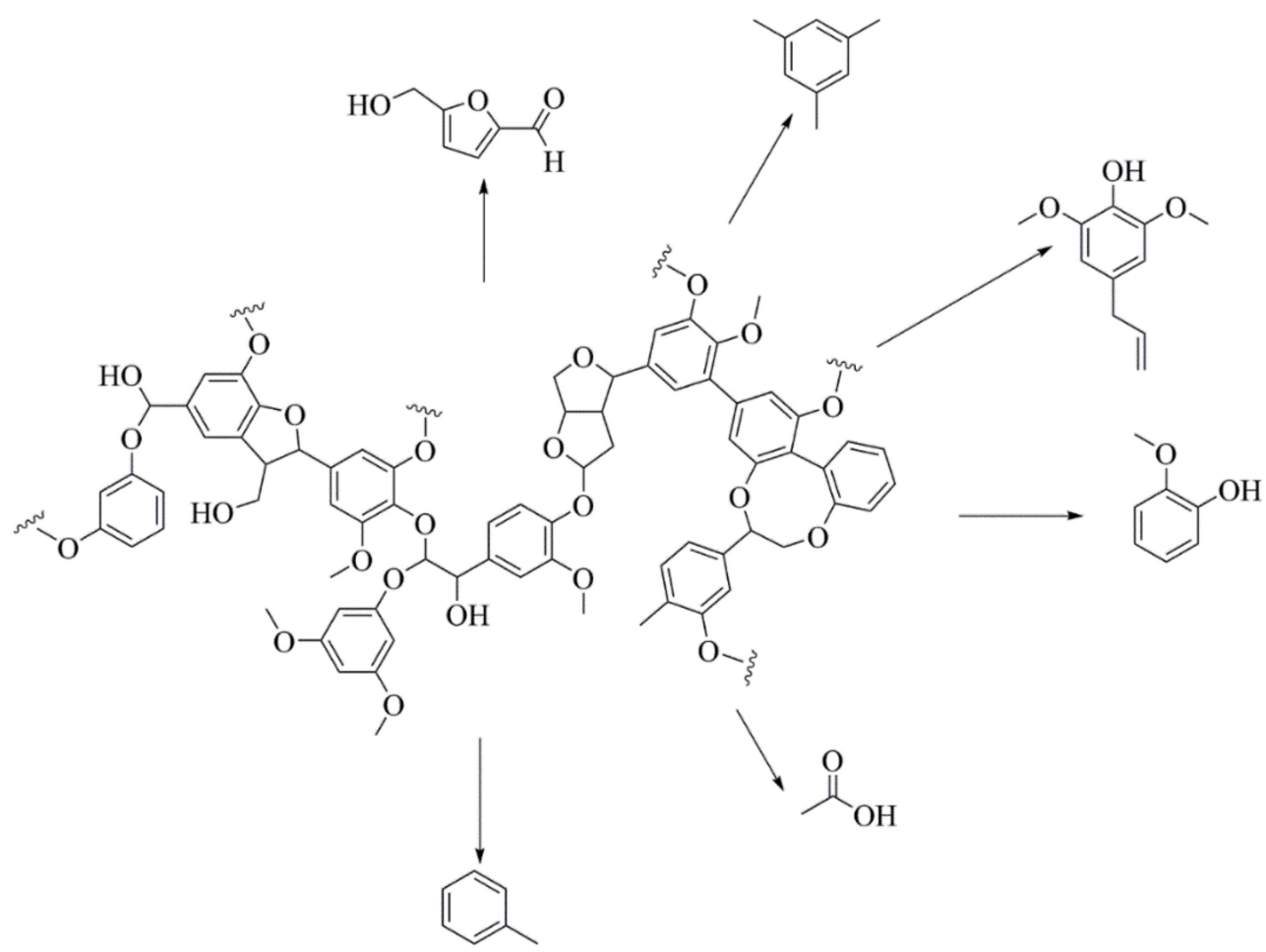

Figure 3. Schematic representation of lignin degradation under pyrolytic conditions. Main products are herein displayed.

The authors suggested that very high molecular weight lignin fragments together with tiny carbon particles were dragged up from bulk by the fast release of volatile organic matter due to the reduced pressure applied. In the gas phase, lignin fragments underwent further degradation reactions [71,72], forming light lignin pyrolysis products and other carbon particles [73]. Carbon particles promoted further cracking reaction with an incremental production of char and advanced pyrolysis compounds [74]. As in the case of reduced pressure MAP of poly(styrene) [73], a good balance between pressure and bio-oils quality was achieved with a bio-oils yield of $44 \mathrm{wt} . \%$. 


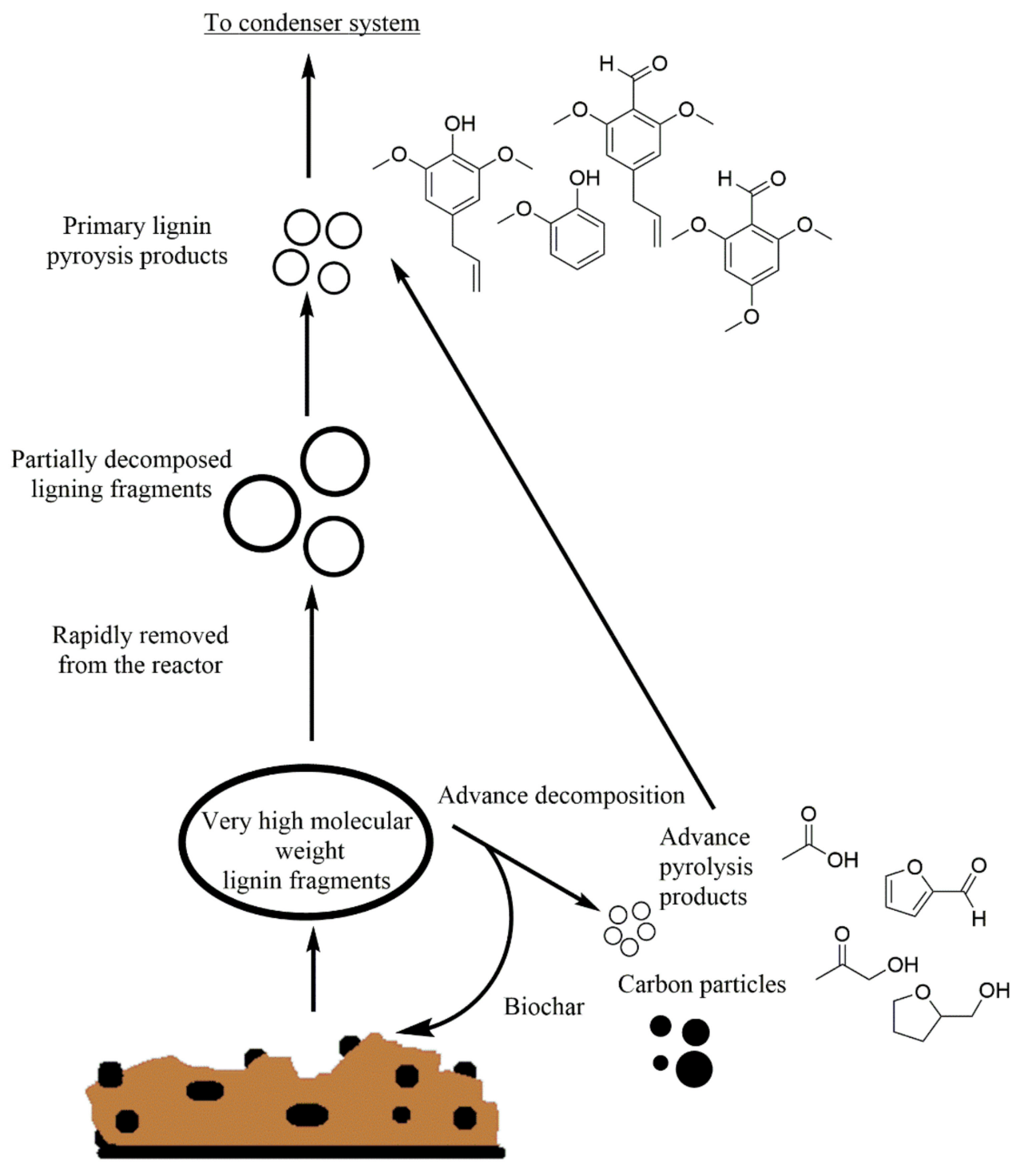

Lignin/absorber

Figure 4. Schematic representation of gas-phase degradation pathways of lignin during reduced pressure MAP as reported by Bartoli et al. [70].

\subsection{MAP of Woody Biomass}

Among lignocellulosic biomasses, woody ones are the largest available worldwide, with an estimated mass of up to 1000 billion tons [75].

Wood is exploited as raw material for structural timber [76], furniture [77], and pulp [78] and also for energy production, even if only as pellets in industrialized countries [79].

Wood is defined as the inner tissue of stems, branches, and roots of perennial plants, and it is classified into hardwood and softwood. Hardwood is wood from angiosperm trees, while softwood is from gymnosperm trees.

Woody biomasses are composed of cellulose, lignin, hemicellulose, organic compounds (i.e., terpenes, alkaloids, fatty acids), and inorganic species.

The amount of each wood component is affected by several parameters such as the species [80] and among each species by the composition of the soil [81], the climate [82], and the harvest period [83].

MAP of woody biomasses produced bio-oils containing an array of compounds regrouped in numerous categories represented by volatile polar and non-polar compounds, 
monolignols, polar compounds with moderate volatility, sugars and anhydrosugars, extractive species, and heavy polar and non-polar compounds [84]. A comprehensive qualitative and quantitative bio-oils analysis is very hard to perform, and generally, only a merely qualitative investigation was reported [85-87]. The complexity of bio-oils mixtures discourages the quantitative analysis based on calibration curves due to the great number of components and their difficult identification. During the last years, some authors described analytical approaches for the theoretical evaluation of relative response factors after identification of bio-oils components through mass spectroscopy, simultaneously performing a qualitative and quantitative analysis [88-90]. Despite their complexity, the study bio-oils produced from lignocellulosic feedstocks has gained great interest.

Huang et al. [91] described the role of the highest temperature reached and heating rate on pyrolysis outputs by treating several woody feedstocks. The authors only reported a qualitative analysis, while a more detailed study was reported by Gao et al. [92]. The authors described the distribution of polychlorinated polycyclic aromatics (PPAs) during biomass MAP. PPAs are produced through the chlorination of simple aromatic rings at elevated temperatures in an oxygen-poor atmosphere in the presence of inorganic or organic chlorine species $[93,94]$. These conditions were achieved during pyrolysis of woody feedstocks, and identification and quantification of PPAs became important due to their toxicity, as reported by Harvey et al. [95]. The authors identified polyhalogenated aromatic compounds in all the fractions collected, estimating their concentration using the nanomolar scale. This was a solid example of the accuracy that could be reached by a quantitative characterization using traditional analytical approaches considering only a small set of compounds.

A general study about the overall properties of bio-oils was produced by Martín et al. [96]. The authors properly described the composition of bio-oils obtained from MAP of numerous Mediterranean biomasses through gas chromatography coupled with mass spectrometry (GC/MS) and by analyzing their rheological properties.

Rajasekhar and Vinu [97] investigated the composition of bio-oils recovered from copyrolysis of high ash Indian coal and rice husk showing cross-reactivity from woody and coal pyrolytic compounds. The authors suggested that single ring aromatic compounds produced from lignin degradation underwent condensation with polyaromatics formed by degradation of coal. This led to the formation of alkyl multi-substituted polyaromatic products detected into bio-oils.

Moving from analysis of bio-oils, several issues are still on the discussion for bio-oils optimization during MAP, such as reactor conceptualization, feedstock variability, and economical aspects.

Mutsengerere et al. [23] proposed a comprehensive description of the influence of all parameters affecting bio-oils yield and quality. The authors identified the pyrolysis temperature, MW power applied, feedstock size, and type of MW absorber as relevant for bio-oils production. Vapor retention time, kind of carrier gas, and the flow rate less affected the bio-oil amount and quality. Even if the effect of a single parameter can be rationalized by running several experiments, the complex interaction of MAP parameters could be satisfyingly investigated only by using computation approaches as reported by Ismail et al. [98]. The authors approached this problem by using a response surface methodology based on a central composite rotatable design. Theoretical prevision on yield and calorific values were in good agreement with empirical data. Nonetheless, there has not yet been developed a fully comprehensive model to explain in detail the relationship between all the operative conditions during MAP and bio-oils outputs. In this way, several studies evaluated a limited set of parameters trying to define the possible correlations.

Wood residues from poplar cultivation were used by Bartoli et al. [25] for the evaluation of the effect of stump-roots and leaves using a multimode batch MW reactor. The authors studied the effect of parameters such as particle size, MW susceptor, and vapor residence time. They reported different effects considering iron of carbon-based material as MWs absorbers. The combination of iron and wood chips improved the yields of gas 
and biochar, while the fine particle size and a carbon-based MW absorber magnified the bio-oil yield. The authors extended the conclusion of this study by testing several biomass waste-streams such as grapes cuts [99] and olive prunings [100]. As general conclusions, the authors proved that a rich radical environment provided metals of strong bases, and iron or sodium reduced the formation of bio-oils with a magnification of water, furans, and acetic acid yields.

Liu et al. [101] evaluated the different results achieved using MWs and classical heating in a fluidized bed auger type reactor. The authors clearly reported a decrement in carbon dioxide content in the gas recovered during MAP.

Salema et al. [102] investigated the performances of a reactor equipped with an overhead stirrer for the conversion of oil palm shell into a phenolic-rich bio-oil. The authors compared the bio-oils production outputs with those achieved using a stationary batch oven reporting better performances for MAP. They hypothesized that was due to higher interaction between the MWs and the suspended particles rather than ones included in the feedstock bulk.

Beneroso et al. [103] reported a comprehensive overview of the issues related to scalability concepts of large MW reactors on the industrial scale for biomass pyrolysis. The authors clearly reported that several issues should be addressed before the large-scale application of MAP will be implemented, such as the high-density power required by the units (greater than $10^{7} \mathrm{~W} / \mathrm{m}^{3}$ ) to avoid the addition of any MWs susceptors. Furthermore, MWs pyrolytic reactors are not easy to assemble as a continuous unit instead of batch one. Accordingly, Salema et al. [104] realized a batch reactor operating at $2.45 \mathrm{GHz}$ was able to convert a huge quantity of wood briquette, reporting good bio-oil yields of up to $40 \mathrm{wt}$ \% without the addition of any MW absorbers. This system was promising, but the bio-oil quality lacked due to a poor heating value of around $3 \mathrm{MJ} / \mathrm{kg}$ as a consequence of a high-water content. The great water content was reasonably due to an inefficient heating process caused by the limited penetration of MWs inside the feedstock bulk. The depth reached by MWs during the pyrolytic process is another factor that is not yet fully addressed by the present reactor technology. A promising step forward is represented by the technology developed by Tyrebirth [105], but it is limited to tire processing.

A continuous reactor for fast MAP was developed by Wang et al. [106] for achieving bio-oil production of up to $30 \mathrm{wt}$ \%. In this case, the authors developed a lab-scale unit without considering an industrial scale-up. Further reactor improvements can be represented by also using the reactor walls to enhance the MW efficiency as reported by Hussain et al. [107] using an aluminum coil reactor and by Bashir et al. [108] using a steel reactor. This was possible because some metals are able to reflect MWs, magnifying their intensity.

Apart from reactors, feedstocks play a very relevant role in bio-oil composition. Undri et al. [24] converted pellets of pine woods using different MW adsorbers recovering a two-phase bio-oil. The upper watery phases were composed of furans, sugars, and sugar derivatives together with a generous amount of acetic acid, while the bottom phases contained a large amount of functionalized phenols.

Similarly, Halim et al. [109] studied Malaysian wood pellets MAP using two maximum temperatures of 775 and $1075 \mathrm{~K}$, respectively. The authors enlighten the possibility to increase bio-oil selectively and/or biochar production.

A scale-up of the pellets MAP was reported by Nhuchhen et al. [110], showing a complex interaction between feedstock properties and MW power.

Abas and co-workers [111] developed an optimized conversion of oil palm fibers producing bio-oils rich in functionalized aromatic compounds. The authors reported a biooil yield of $41 \mathrm{wt}$.\% with content of aromatic components up to $73 \%$ and remarkably gallic acid concentration of up to $2.6 \mathrm{wt}$.\%. Mushtaq and co-workers [112] converted oil palm shells mixed with MW susceptors obtained from coconut-activated carbon achieving a great production of bio-oil rich in phenolic derivatives up to $54 \%$ of identified compounds. 
Bartoli et al. [113] described the pyrolytic conversion of Arundo donax cultivation residues for MW with a great biochar yield of up to $63 \mathrm{wt} . \%$ by using rhyzomes, while MAP of leaves promotes the formation of bio-oil up to $41 \mathrm{wt} . \%$. Remarkably, bio-oils produced were recovered as one-phase dark brown liquids with a high content of aromatic compounds and levoglucosan up to $48 \mathrm{~g} / \mathrm{L}$. The common phase separation phenomena generally observed was prevented by furans that acted as phase mixers and stabilizers.

Another cane-type feedstock of MAP is the bamboo family. Dong et al. [114] reported the MAP of Moso bamboo by using bamboo-derived biochar as an MWs susceptor. The authors collected bio-oils rich in acetic acid and phenol with concentrations up to $73 \%$ to $83 \%$, respectively.

An interesting effect on bamboo bio-oil quality can be achieved using iron salt as MW absorbers, depleting the bio-oil yield and magnifying a methane-rich gas formation [115]. These results can also be exploited by the iron sites anchored to the activated carbon surface [116] by enforcing a chemical functionalization process. Nonetheless, post-treatment required a multi-step conversion apparatus that can decrease the appealing of the overall process. Accordingly, as an alternative to post-pyrolysis catalytic upgrading, several authors investigated feedstock pre-treatments for improving bio-oil properties such as viscosity, heating value, and water content.

Tarves et al. [117] treated shrub willow by using a hot water extractive process, achieving similar bio-oil yields compared with untreated feedstock. The authors reported significantly improved fuel quality for bio-oil recovered after MAP of treated willow due to an increment of aromatic content and lower levoglucosan amounts.

An acidic wash pre-treatment was reported by Feng et al. [118] using formic acid magnifying bio-oil yields together and reducing biochar production due to the ash depletion.

Advance cracking process can be induced by the use of potassium hydroxide, as reported by Grycova et al. [119]. The authors collected a bio-oil rich in aromatics and observed an in-situ activation of biochar.

Metal salts containing copper or zinc sulfate have been used to promote the production of levoglucosenone using ash juniper waste [120].

Wan et al. [121] reported the effect of a wide range of metal-based inorganic species on corn stover and aspen wood reporting and improvement of bio-oil yields, particularly by using chloride salts. This was due to the advanced cracking reactions promoted by the chloride species.

Similarly, a combination of phosphate-containing salts was very effective for the enhancement of bio-oil yields [122-124]. This effect was due to the cracking induced by phosphate bundles, as reported by many publications [125-127].

Bartoli et al. [100] described a curious phenomenon related to the reactivity induced by sodium hydroxide during the MAP conversion of woody biomasses. The authors observed an increment of acetic acid production by using sodium hydroxide instead of carbon-based MWs susceptors. They suggested that advanced cracking of organic species occurred in the gas phase instead of bulk.

Generally, pre-treatments of feedstock with salts led to a more efficient cracking process with the reduction of the oxygen content of bio-oils and complex compounds such as levoglucosan.

Another strategy of bio-oil upgrading is by the use of zeolites [128] such as ZSM5 [67,129-138] exploiting the double role of the MW absorber and cracking promoter.

In addition, structured inorganic species can use as reported by Zhang et al. [139]. The authors reported the ex-situ reactor upgrading bio-oil over Ce-doped $\gamma-\mathrm{Al}_{2} \mathrm{O}_{3} / \mathrm{ZrO}_{2}$, achieving an improvement of hydrocarbon content.

\section{MAP of Non-Lignocellulosic Biomasses}

MW-induced cracking of non-lignocellulosic biomasses is a new and very attractive research field in the great realm of biomass conversions. The exploration of alternative sources to lignocellulosic feedstock is mainly due to the high oxygen content of derived bio- 
oils. This can be reduced only by additional treatments such as catalytic upgrading [140] or fractional condensation [141,142]. Nonetheless, non-woody feedstocks have been studied to produce a bio-oil [143] close to the drop-in fuel requirements. Accordingly, fatty acids are one of the most attractive feedstocks due to their composition and product distribution of bio-oils recovered after their cracking [144]. Native fatty acids are composed of carboxylic groups connected to a long saturated or unsaturated carbon chain and to a polyalcohol. These species can undergo thermal degradation according to the scheme shown in Figure 5.

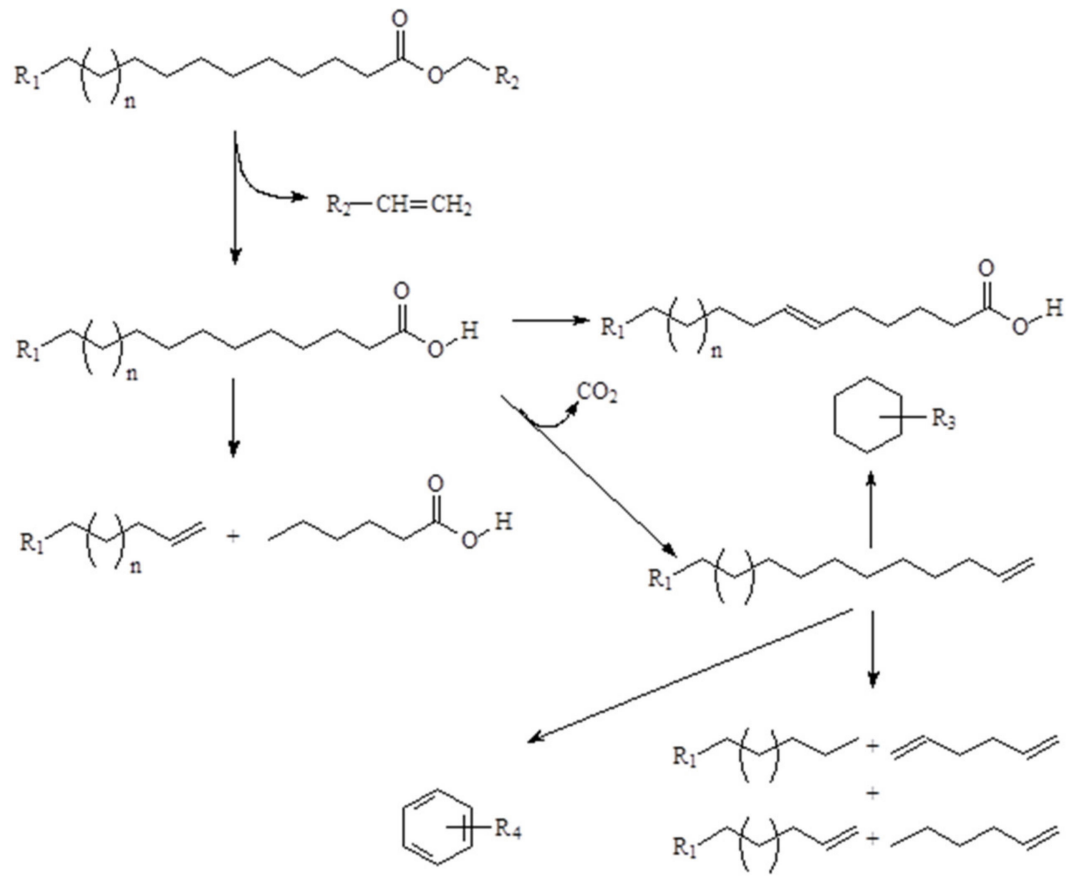

Figure 5. Radical degradative route of fatty acids under pyrolytic conditions.

The radical cleavage of the fatty acid carboxylic group represents the first stage of the formation of saturated and unsaturated hydrocarbons during their pyrolysis. Biooils collected from fat pyrolysis are very close to drop-in fuels able to replace diesel-like combustibles.

Wang et al. [145] studied the effect of different alkyl chains on fatty acids cracking during MAP. To simplify the process, the authors treated fatty acid salts formed after reaction with sodium hydroxide. Contrary to native fatty acids, fatty acid salts were able to absorb MWs and underwent cracking degradation, leading to the formation of cyclic hydrocarbons, saturated and unsaturated linear hydrocarbons, and a relevant amount of aromatics compounds.

MAP of native fatty acids has another unneglectable issue related to the presence of glycerol directly bonded to their carboxylic ends. Nonetheless, the presence of glycerol can lead to the formation of some compounds acting as proper fuel additives improving, the oil quality as reported by $\mathrm{Ng}$ et al. [146].

Rapeseed oil is an alternative feedstock for pyrolytic conversion, as clearly reported by Omar et al. [147]. The authors compared MAP outputs with traditional fast pyrolysis by using temperatures ranging from 775 to $875 \mathrm{~K}$. They recovered diesel-like liquid containing a mixture of aromatics, linear, cyclic, saturated, and unsaturated hydrocarbons; acids; and other oxygenated products. Compared to traditional pyrolysis, MAP led to an increment of aromatics in the liquid fraction.

Recently, algae have collected great attention due to their high lipidic content [148]. Several researches reported MAP conversion of microalgae with the production of a hydrocarbonrich bio-oil [149-151] and their use in co-pyrolytic processes with biomasses [152-154]. Fur- 
thermore, to obtain bio-oils from the algae MAP, several authors ran catalytic upgrading using zeolite materials aiming to improve the aromatic content [155-157].

Another interesting feedstock is waste food, firstly investigated by Kadlimatti et al. [158] with pioneering research published in 2019. The authors achieved a bio-oil yield of up to $30 \mathrm{wt}$ \% displaying a product distribution with some hazardous species such as methylphosphine, 2-fluoro-propane, trimethylsilyl methyl sulfide, and 1,3-bis(2-hydroxymethyl)urea. Nonetheless, they reported very promising heating values of bio-oil close to $24 \mathrm{MJ} / \mathrm{kg}$.

\section{MAP Biomasses and Plastics: A Co-Pyrolysis Approach}

Co-pyrolysis is a reliable approach to improve the overall fuel properties of bio-oils by reducing their oxygen content. This was achieved by the simultaneous thermal degradation of biomasses together with polyolefins leading to the production of a hydrocarbon-rich liquid fraction as the consequence of radical degradation shown in Figure 6.

a)

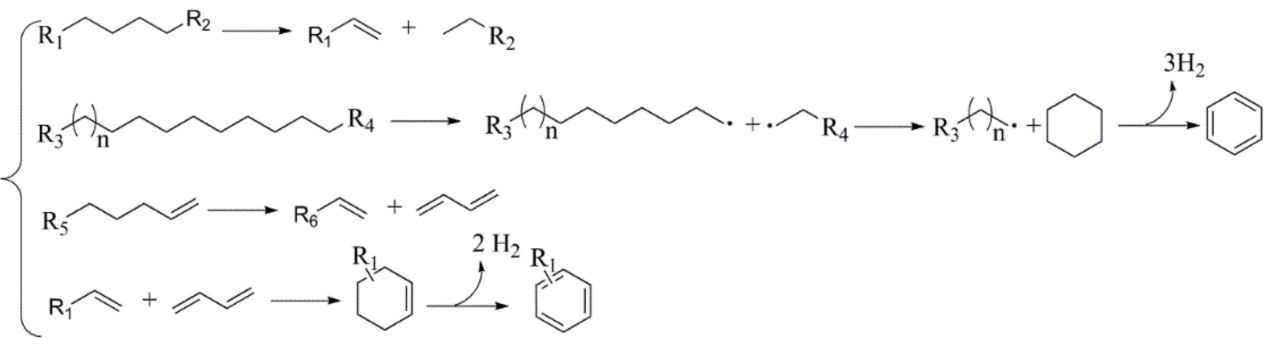

b)

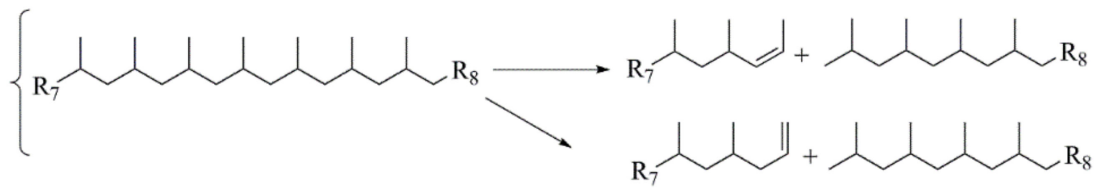

c)

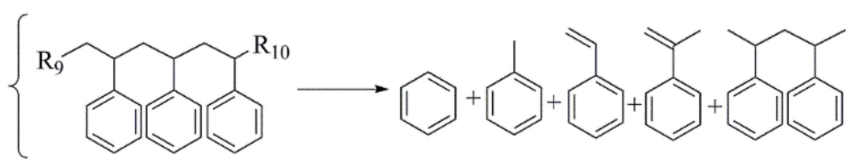

Figure 6. Radical degradation routes of (a) poly(ethylene), (b) poly(propylene), and (c) poly(styrene) under pyrolytic conditions.

Chen et al. [159] described MAP of high-density poly(ethylene) and cellulosic biomass recovered by newspaper waste stream. The authors reported an increment of bio-oil production up to $32 \mathrm{wt} . \%$ from the $20 \mathrm{wt}$.\% yield estimated through thermogravimetrical analysis technique together with a reduction of viscosity and bio-oils acidity. Zhao et al. [160] firstly studied the fast MW-induced co-pyrolysis of poly(propylene) and bamboo, claiming a bio-oil yield of $62 \mathrm{wt}$ \% with high content. Furthermore, Suriapparo et al. [161] evaluated the co-pyrolysis of biomasses with polyolefins (i.e., poly(styrene) and poly(propylene)), producing a bio-oil with an aromatic content of $54 \mathrm{wt} . \%$ and highest heating value of $42 \mathrm{MJ} / \mathrm{kg}$.

\section{Conclusions}

Thermal conversion of biomass is, without any doubt, one of the most attractive approaches to lead change in current productive commodities. Increased need for efficient technologies may open the way to spreading the use of MAP technologies from lab-scale units to industrial-scale plants. At present, this goal is far from being achieved by the use of biomass residues due to the great complexity of bio-oils and the challenging scalability of the pyrolysis reactors.

Nevertheless, compound classes such as anhydrosugars, phenols, furans, or small organic acids can be isolated and used as alternative solvents, additives for materials 
science, or directly as fuel. Bio-oil composition could be partially tuned by selecting the feedstock and by tuning the conversion parameters, thus achieving an overall improvement in aromatics or furan productivity. Selective production of anhydrosugars still remains to be accomplished due to their fast degradative rate in pyrolytic conditions. MAP is a difficult tool to tune for the production of specific chemicals, but it could be a very powerful resource for the production of fuel. This purpose has been reached by the combination of non-lignocellulosic biomasses and catalytic upgrading. Even if this approach never replaces the oil-based platform, it will help mitigate waste management risk by using waste-streams as feedstocks. MAP technology is still in development, and an application is not yet proposed, but we firmly believe that it will play a crucial role in the improvement of sustainability.

Author Contributions: Conceptualization, M.B. and M.G.; writing—original draft preparation, M.B., M.G., O.D., G.S. and M.F.; writing—review and editing, M.G., O.D., G.S. and M.F.; supervision, M.B. All authors have read and agreed to the published version of the manuscript.

Conflicts of Interest: The authors declare no conflict of interest.

\section{References}

1. Karl, T.R.; Trenberth, K.E. Modern global climate change. Science 2003, 302, 1719-1723. [CrossRef] [PubMed]

2. Hill, M.K. Understanding Environmental Pollution; Cambridge University Press: Cambridge, UK, 2010.

3. Qualman, D. Global Plastics Production, 1917 to 2050. Available online: https://www.darrinqualman.com/global-plasticsproduction (accessed on 3 March 2021).

4. Geyer, R.; Jambeck, J.R.; Law, K.L. Production, use, and fate of all plastics ever made. Sci. Adv. 2017, 3, e1700782. [CrossRef]

5. De Castro, C.; Miguel, L.J.; Mediavilla, M. The role of non conventional oil in the attenuation of peak oil. Energy Policy 2009, 37, 1825-1833. [CrossRef]

6. Artz, J.; Palkovits, R. Cellulose-based platform chemical: The path to application. Curr. Opin. Green Sustain. Chem. 2018, 14, 14-18. [CrossRef]

7. Das, O.; Kim, N.K.; Hedenqvist, M.S.; Lin, R.J.; Sarmah, A.K.; Bhattacharyya, D. An attempt to find a suitable biomass for biochar-based polypropylene biocomposites. Environ. Manag. 2018, 62, 403-413. [CrossRef] [PubMed]

8. Das, O.; Hedenqvist, M.S.; Johansson, E.; Olsson, R.T.; Loho, T.A.; Capezza, A.J.; Raman, R.S.; Holder, S. An all-gluten biocomposite: Comparisons with carbon black and pine char composites. Compos. Part A Appl. Sci. Manuf. 2019, 120, 42-48. [CrossRef]

9. Barbalini, M.; Bartoli, M.; Tagliaferro, A.; Malucelli, G. Phytic Acid and Biochar: An Effective All Bio-Sourced Flame Retardant Formulation for Cotton Fabrics. Polymers 2020, 12, 811. [CrossRef] [PubMed]

10. Arrigo, R.; Bartoli, M.; Malucelli, G. Poly (lactic Acid)-Biochar Biocomposites: Effect of Processing and Filler Content on Rheological, Thermal, and Mechanical Properties. Polymers 2020, 12, 892. [CrossRef]

11. Giorcelli, M.; Bartoli, M. Development of Coffee Biochar Filler for the Production of Electrical Conductive Reinforced Plastic. Polymers 2019, 11, 17. [CrossRef]

12. Bartoli, M.; Giorcelli, M.; Rosso, C.; Rovere, M.; Jagdale, P.; Tagliaferro, A. Influence of Commercial Biochar Fillers on Brittleness/Ductility of Epoxy Resin Composites. Appl. Sci. 2019, 9, 13. [CrossRef]

13. Ferrero, G.; Maniatis, K.; Buekens, A.; Bridgwater, A. Pyrolysis and Gasification; Elsevier Applied Science: New York, NY, USA, 1989.

14. Bridgwater, A.V.; Meier, D.; Radlein, D. An overview of fast pyrolysis of biomass. Org. Geochem. 1999, 30, 1479-1493. [CrossRef]

15. Scheirs, J.; Kaminsky, W. Feedstock Recycling and Pyrolysis of Waste Plastics; John Wiley \& Sons Chichester: London, UK, 2006.

16. Weber, K.; Quicker, P. Properties of biochar. Fuel 2018, 217, 240-261. [CrossRef]

17. Bartoli, M.; Giorcelli, M.; Jagdale, P.; Rovere, M.; Tagliaferro, A. A Review of Non-Soil Biochar Applications. Materials 2020, 13, 261. [CrossRef]

18. Laurent, E.; Pierret, C.; Keymeulen, O.; Delmon, B. Hydrodeoxygenation of oxygenated model compounds: Simulation of the hydro-purification of bio-oils. In Advances in Thermochemical Biomass Conversion; Springer: London, UK, 1993; pp. 1403-1414.

19. Wang, S.; Gu, Y.; Liu, Q.; Yao, Y.; Guo, Z.; Luo, Z.; Cen, K. Separation of bio-oil by molecular distillation. Fuel Process. Technol. 2009, 90, 738-745. [CrossRef]

20. Patel, R.N.; Bandyopadhyay, S.; Ganesh, A. Extraction of cardanol and phenol from bio-oils obtained through vacuum pyrolysis of biomass using supercritical fluid extraction. Energy 2011, 36, 1535-1542. [CrossRef]

21. Mohan, D.; Shi, J.; Nicholas, D.D.; Pittman, C.U., Jr.; Steele, P.H.; Cooper, J.E. Fungicidal values of bio-oils and their lignin-rich fractions obtained from wood/bark fast pyrolysis. Chemosphere 2008, 71, 456-465. [CrossRef]

22. Undri, A.; Rosi, L.; Frediani, M.; Frediani, P. Microwave Pyrolysis of Polymeric Materials; Chandra, U., Ed.; IntechOpen: London, UK, 2011. 
23. Mutsengerere, S.; Chihobo, C.; Musademba, D.; Nhapi, I. A review of operating parameters affecting bio-oil yield in microwave pyrolysis of lignocellulosic biomass. Renew. Sustain. Energy Rev. 2019, 104, 328-336. [CrossRef]

24. Undri, A.; Zaid, M.; Briens, C.; Berruti, F.; Rosi, L.; Bartoli, M.; Frediani, M.; Frediani, P. Bio-oil from pyrolysis of wood pellets using a microwave multimode oven and different microwave absorbers. Fuel 2015, 153, 464-482. [CrossRef]

25. Bartoli, M.; Rosi, L.; Giovannelli, A.; Frediani, P.; Frediani, M. Bio-oil from residues of short rotation coppice of poplar using a microwave assisted pyrolysis. J. Anal. Appl. Pyrolysis 2016, 119, 224-232. [CrossRef]

26. Bartoli, M.; Rosi, L.; Giovannelli, A.; Frediani, P.; Frediani, M. Pyrolysis of a-cellulose in a microwave multimode batch reactor. J. Anal. Appl. Pyrolysis 2016, 120, 284-296. [CrossRef]

27. Metaxas, A.; Meredith, R.J. Industrial Microwave Heating; IET: London, UK, 1983.

28. Pozar, D.M. Microwave Engineering; John Wiley \& Sons: New York, NY, USA, 2009.

29. Rosenkranz, P.W. Water vapor microwave continuum absorption: A comparison of measurements and models. Radio Sci. 1998, 33, 919-928. [CrossRef]

30. Guo, X.; Deng, Y.; Gu, D.; Che, R.; Zhao, D. Synthesis and microwave absorption of uniform hematite nanoparticles and their core-shell mesoporous silica nanocomposites. J. Mater. Chem. 2009, 19, 6706-6712. [CrossRef]

31. Clark, D.E.; Folz, D.C.; West, J.K. Processing materials with microwave energy. Mater. Sci. Eng. A 2000, 287, 153-158. [CrossRef]

32. Wu, R.; Zhou, K.; Yang, Z.; Qian, X.; Wei, J.; Liu, L.; Huang, Y.; Kong, L.; Wang, L. Molten-salt-mediated synthesis of SiC nanowires for microwave absorption applications. CrystEngComm 2013, 15, 570-576. [CrossRef]

33. Ni, Z.; Masel, R.I. Rapid production of metal-organic frameworks via microwave-assisted solvothermal synthesis. J. Am. Chem. Soc. 2006, 128, 12394-12395. [CrossRef]

34. Kingman, S.; Rowson, N. Microwave treatment of minerals-a review. Miner. Eng. 1998, 11, 1081-1087. [CrossRef]

35. Robinson, J.P.; Kingman, S.W.; Barranco, R.; Snape, C.E.; Al-Sayegh, H. Microwave Pyrolysis of Wood Pellets. Ind. Eng. Chem. Res. 2010, 49, 459-463. [CrossRef]

36. Bartoli, M.; Frediani, F.; Briens, C.; Berruti, F.; Rosi, L. An Overview of Temperature Issues in Microwave-Assisted Pyrolysis. Processes 2019, 7, 658. [CrossRef]

37. Stefanidis, S.D.; Kalogiannis, K.G.; Iliopoulou, E.F.; Michailof, C.M.; Pilavachi, P.A.; Lappas, A.A. A study of lignocellulosic biomass pyrolysis via the pyrolysis of cellulose, hemicellulose and lignin. J. Anal. Appl. Pyrolysis 2014, 105, 143-150. [CrossRef]

38. Zhang, J.; Choi, Y.S.; Yoo, C.G.; Kim, T.H.; Brown, R.C.; Shanks, B.H. Cellulose-Hemicellulose and Cellulose-Lignin Interactions during Fast Pyrolysis. Acs Sustain. Chem. Eng. 2015, 3, 293-301. [CrossRef]

39. O'Sullivan, A.C. Cellulose: The structure slowly unravels. Cellulose 1997, 4, 173-207. [CrossRef]

40. Sjostrom, E. Wood Chemistry: Fundamentals and Applications; Elsevier: Amsterdam, The Netherlands, 2013.

41. Budarin, V.L.; Clark, J.H.; Lanigan, B.A.; Shuttleworth, P.; Macquarrie, D.J. Microwave assisted decomposition of cellulose: A new thermochemical route for biomass exploitation. Bioresour. Technol. 2010, 101, 3776-3779. [CrossRef]

42. Zhang, X.; Yang, W.; Dong, C. Levoglucosan formation mechanisms during cellulose pyrolysis. J. Anal. Appl. Pyrolysis 2013, 104, 19-27. [CrossRef]

43. Zhang, X.; Li, J.; Yang, W.; Blasiak, W. Formation Mechanism of Levoglucosan and Formaldehyde during Cellulose Pyrolysis. Energy Fuels 2011, 25, 3739-3746. [CrossRef]

44. Miura, M.; Kaga, H.; Yoshida, T.; Ando, K. Microwave pyrolysis of cellulosic materials for the production of anhydrosugars. J. Wood Sci. 2001, 47, 502-506. [CrossRef]

45. Chen, L.; Liao, Y.; Guo, Z.; Cao, Y.; Ma, X. Products distribution and generation pathway of cellulose pyrolysis. J. Clean. Prod. 2019, 232, 1309-1320. [CrossRef]

46. Wang, W.; Wang, M.; Huang, J.; Tang, N.; Dang, Z.; Shi, Y.; Zhaohe, M. Microwave-assisted catalytic pyrolysis of cellulose for phenol-rich bio-oil production. J. Energy Inst. 2018. [CrossRef]

47. Al Shra'ah, A.; Helleur, R. Microwave pyrolysis of cellulose at low temperature. J. Anal. Appl. Pyrolysis 2014, 105, 91-99. [CrossRef]

48. Zhang, Z.; Matharu, A.S. Chapter 23-Thermochemical Valorization of Paper Deinking Residue through Microwave-Assisted Pyrolysis. In Waste Biorefinery; Bhaskar, T., Pandey, A., Mohan, S.V., Lee, D.-J., Khanal, S.K., Eds.; Elsevier: Amserdam, The Netherlands, 2018.

49. Undri, A.; Rosi, L.; Frediani, M.; Frediani, P. Fuel from microwave assisted pyrolysis of waste multilayer packaging beverage. Fuel 2014, 133, 7-16. [CrossRef]

50. Namazi, A.B.; Allen, D.G.; Jia, C.Q. Probing microwave heating of lignocellulosic biomasses. J. Anal. Appl. Pyrolysis 2015, 112, 121-128. [CrossRef]

51. Huang, Y.-F.; Chiueh, P.-T.; Kuan, W.-H.; Lo, S.-L. Effects of lignocellulosic composition and microwave power level on the gaseous product of microwave pyrolysis. Energy 2015, 89, 974-981. [CrossRef]

52. Yang, H.; Yan, R.; Chen, H.; Zheng, C.; Lee, D.H.; Liang, D.T. In-Depth Investigation of Biomass Pyrolysis Based on Three Major Components: Hemicellulose, Cellulose and Lignin. Energy Fuels 2006, 20, 388-393. [CrossRef]

53. Patwardhan, P.R.; Brown, R.C.; Shanks, B.H. Product distribution from the fast pyrolysis of hemicellulose. ChemSusChem 2011, 4, 636-643. [CrossRef] 
54. Li, T.; Remón, J.; Shuttleworth, P.S.; Jiang, Z.; Fan, J.; Clark, J.H.; Budarin, V.L. Controllable production of liquid and solid biofuels by doping-free, microwave-assisted, pressurised pyrolysis of hemicellulose. Energy Convers. Manag. 2017, 144, 104-113. [CrossRef]

55. Hatakeyama, H.; Hatakeyama, T. Lignin structure, properties, and applications. In Biopolymers; Advances in Polymer Science; Springer: Berlin, Germany, 2009; pp. 1-63.

56. Das, O.; Sarmah, A.K. Value added liquid products from waste biomass pyrolysis using pretreatments. Sci. Total Environ. 2015, 538, 145-151. [CrossRef] [PubMed]

57. Chakar, F.S.; Ragauskas, A.J. Review of current and future softwood kraft lignin process chemistry. Ind. Crop. Prod. 2004, 20, 131-141. [CrossRef]

58. Pye, E.K. Industrial lignin production and applications. Biorefineries-Industrial Processes and Products: Status quo and Future Directions; Kamm, B., Gruber, P.R., Kamm, M., Eds.; Wiley: London, UK, 2006; pp. 165-200.

59. Kawamoto, H. Lignin pyrolysis reactions. J. Wood Sci. 2017, 63, 117. [CrossRef]

60. Farag, S.; Fu, D.; Jessop, P.G.; Chaouki, J. Detailed compositional analysis and structural investigation of a bio-oil from microwave pyrolysis of kraft lignin. J. Anal. Appl. Pyrolysis 2014, 109, 249-257. [CrossRef]

61. Farag, S.; Kouisni, L.; Chaouki, J. Lumped approach in kinetic modeling of microwave pyrolysis of kraft lignin. Energy Fuels 2014, 28, 1406-1417. [CrossRef]

62. Fan, L.; Song, H.; Lu, Q.; Leng, L.; Li, K.; Liu, Y.; Wang, Y.; Chen, P.; Ruan, R.; Zhou, W. Screening microwave susceptors for microwave-assisted pyrolysis of lignin: Comparison of product yield and chemical profile. J. Anal. Appl. Pyrolysis 2019, 144, 14623-14631. [CrossRef]

63. Brebu, M.; Vasile, C. Thermal degradation of lignin-A review. Cellul. Chem. Technol. 2010, 44, 353.

64. Yerrayya, A.; Suriapparao, D.V.; Natarajan, U.; Vinu, R. Selective production of phenols from lignin via microwave pyrolysis using different carbonaceous susceptors. Bioresour. Technol. 2018, 270, 519-528. [CrossRef]

65. Farag, S.; Mudraboyina, B.P.; Jessop, P.G.; Chaouki, J. Impact of the heating mechanism on the yield and composition of bio-oil from pyrolysis of kraft lignin. Biomass Bioenergy 2016, 95, 344-353. [CrossRef]

66. Duan, D.; Wang, Y.; Dai, L.; Ruan, R.; Zhao, Y.; Fan, L.; Tayier, M.; Liu, Y. Ex-situ catalytic co-pyrolysis of lignin and polypropylene to upgrade bio-oil quality by microwave heating. Bioresour. Technol. 2017, 241, 207-213. [CrossRef]

67. Fan, L.; Chen, P.; Zhang, Y.; Liu, S.; Liu, Y.; Wang, Y.; Dai, L.; Ruan, R. Fast microwave-assisted catalytic co-pyrolysis of lignin and low-density polyethylene with HZSM-5 and MgO for improved bio-oil yield and quality. Bioresour. Technol. 2017, 225, 199-205. [CrossRef] [PubMed]

68. Undri, A.; Rosi, L.; Frediani, M.; Frediani, P. Efficient disposal of waste polyolefins through microwave assisted pyrolysis. Fuel 2014, 116, 662-671. [CrossRef]

69. Fan, L.; Chen, P.; Zhou, N.; Liu, S.; Zhang, Y.; Liu, Y.; Wang, Y.; Omar, M.M.; Peng, P.; Addy, M.; et al. In-situ and ex-situ catalytic upgrading of vapors from microwave-assisted pyrolysis of lignin. Bioresour. Technol. 2018, 247, 851-858. [CrossRef] [PubMed]

70. Bartoli, M.; Rosi, L.; Frediani, P.; Frediani, M. Bio-oils from microwave assisted pyrolysis of kraft lignin operating at reduced residual pressure. Fuel 2020, 278, 118175-118186. [CrossRef]

71. Huang, J.; Liu, C.; Wu, D.; Tong, H.; Ren, L. Density functional theory studies on pyrolysis mechanism of $\beta$-O-4 type lignin dimer model compound. J. Anal. Appl. Pyrolysis 2014, 109, 98-108. [CrossRef]

72. Kotake, T.; Kawamoto, H.; Saka, S. Mechanisms for the formation of monomers and oligomers during the pyrolysis of a softwood lignin. J. Anal. Appl. Pyrolysis 2014, 105, 309-316. [CrossRef]

73. Bartoli, M.; Rosi, L.; Frediani, M.; Undri, A.; Frediani, P. Depolymerization of polystyrene at reduced pressure through a microwave assisted pyrolysis. J. Anal. Appl. Pyrolysis 2015, 113, 281-287. [CrossRef]

74. Collard, F.-X.; Blin, J. A review on pyrolysis of biomass constituents: Mechanisms and composition of the products obtained from the conversion of cellulose, hemicelluloses and lignin. Renew. Sustain. Energy Rev. 2014, 38, 594-608. [CrossRef]

75. Pepke, E. Global Wood Markets: Consumption, Production and Trade. In Proceedings of the International Forestry and Global Issues, Nancy, France, 18 May 2018.

76. Thelandersson, S.; Larsen, H.J. Timber Engineering; John Wiley \& Sons: London, UK, 2003.

77. Kaplinsky, R.; Memedovic, O.; Morris, M.; Readman, J. The global wood furniture value chain: What prospects for upgrading by developing countries. Unido Sect. Stud. Ser. Work. Pap. 2003. [CrossRef]

78. Smook, G.A. Handbook for Pulp E Paper Technologists; Canadian Pulp and Paper Association: Atlanta, GA, USA, 1992.

79. Peksa-Blanchard, M.; Dolzan, P.; Grassi, A.; Heinimö, J.; Junginger, M.; Ranta, T.; Walter, A. Global Wood Pellets Markets and Industry: Policy Drivers, Market Status and Raw Material Potential; Iea Bioenergy Task 40; University of Minnesota: Minneapolis, MN, USA, 2007.

80. Lamlom, S.; Savidge, R. A reassessment of carbon content in wood: Variation within and between 41 North American species. Biomass Bioenergy 2003, 25, 381-388. [CrossRef]

81. Demeyer, A.; Nkana, J.V.; Verloo, M. Characteristics of wood ash and influence on soil properties and nutrient uptake: An overview. Bioresour. Technol. 2001, 77, 287-295. [CrossRef]

82. Chave, J.; Muller-Landau, H.C.; Baker, T.R.; Easdale, T.A.; Steege, H.t.; Webb, C.O. Regional and phylogenetic variation of wood density across 2456 neotropical tree species. Ecol. Appl. 2006, 16, 2356-2367. [CrossRef] 
83. Pereira, H. Variability in the chemical composition of plantation eucalypts (Eucalyptus globulus Labill.). Wood Fiber Sci. 2007, 20, 82-90.

84. Garcia-Perez, M.; Chaala, A.; Pakdel, H.; Kretschmer, D.; Roy, C. Characterization of bio-oils in chemical families. Biomass Bioenergy 2007, 31, 222-242. [CrossRef]

85. Ingram, L.; Mohan, D.; Bricka, M.; Steele, P.; Strobel, D.; Crocker, D.; Mitchell, B.; Mohammad, J.; Cantrell, K.; Pittman Jr, C.U. Pyrolysis of wood and bark in an auger reactor: Physical properties and chemical analysis of the produced bio-oils. Energy Fuels 2007, 22, 614-625. [CrossRef]

86. Lu, Q.; Yang, X.-l.; Zhu, X.-f. Analysis on chemical and physical properties of bio-oil pyrolyzed from rice husk. J. Anal. Appl. Pyrolysis 2008, 82, 191-198. [CrossRef]

87. Özbay, N.; Pütün, A.E.; Pütün, E. Structural analysis of bio-oils from pyrolysis and steam pyrolysis of cottonseed cake. J. Anal. Appl. Pyrolysis 2001, 60, 89-101. [CrossRef]

88. Djokic, M.R.; Dijkmans, T.; Yildiz, G.; Prins, W.; Van Geem, K.M. Quantitative analysis of crude and stabilized bio-oils by comprehensive two-dimensional gas-chromatography. J. Chromatogr. A 2012, 1257, 131-140. [CrossRef]

89. Bartoli, M.; Rosi, L.; Frediani, M.; Frediani, P. A simple protocol for quantitative analysis of bio-oils through gaschromatography/mass spectrometry. Eur. J. Mass Spectrom. 2016, 22, 199-212. [CrossRef]

90. Undri, A.; Abou-Zahid, M.; Briens, C.; Berruti, F.; Rosi, L.; Bartoli, M.; Frediani, M.; Frediani, P. A simple procedure for chromatographic analysis of pyrolysis bio-oils. J. Anal. Appl. Pyrolysis 2015, 114, 208-221. [CrossRef]

91. Huang, Y.-F.; Chiueh, P.-T.; Kuan, W.-H.; Lo, S.-L. Product distribution and heating performance of lignocellulosic biomass pyrolysis using microwave heating. Energy Procedia 2018, 152, 910-915. [CrossRef]

92. Gao, Q.; Budarin, V.L.; Cieplik, M.; Gronnow, M.; Jansson, S. PCDDs, PCDFs and PCNs in products of microwave-assisted pyrolysis of woody biomass-Distribution among solid, liquid and gaseous phases and effects of material composition. Chemosphere 2016, 145, 193-199. [CrossRef] [PubMed]

93. Stieglitz, L. Selected topics on the de novo synthesis of PCDD/PCDF on fly ash. Environ. Eng. Sci. 1998, 15, 5-18. [CrossRef]

94. Born, J.G.; Mulder, P.; Louw, R. Fly ash mediated reactions of phenol and monochlorophenols: Oxychlorination, deep oxidation, and condensation. Environ. Sci. Technol. 1993, 27, 1849-1863. [CrossRef]

95. Harvey, R.G. Polycyclic Aromatic Hydrocarbons: Chemistry and Carcinogenicity; CUP Archive: Cambridge, UK, 1991.

96. Martín, M.T.; Sanz, A.B.; Nozal, L.; Castro, F.; Alonso, R.; Aguirre, J.L.; González, S.D.; Matía, M.P.; Novella, J.L.; Peinado, M.; et al. Microwave-assisted pyrolysis of Mediterranean forest biomass waste: Bioproduct characterization. J. Anal. Appl. Pyrolysis 2017, 127, 278-285. [CrossRef]

97. Rajasekhar Reddy, B.; Vinu, R. Microwave-assisted co-pyrolysis of high ash Indian coal and rice husk: Product characterization and evidence of interactions. Fuel Process. Technol. 2018, 178, 41-52. [CrossRef]

98. Ismail, K.; Ishak, M.A.M.; Ab Ghani, Z.; Abdullah, M.F.; Safian, M.T.-u.; Idris, S.S.; Tahiruddin, S.; Yunus, M.F.M.; Hakimi, N.I.N.M. Microwave-assisted pyrolysis of palm kernel shell: Optimization using response surface methodology (RSM). Renew. Energy 2013, 55, 357-365.

99. Bartoli, M.; Rosi, L.; Giovannelli, A.; Frediani, P.; Passaponti, M.; Frediani, M. Microwave assisted pyrolysis of crop residues from Vitis vinifera. J. Anal. Appl. Pyrolysis 2018, 130, 305-313. [CrossRef]

100. Bartoli, M.; Rosi, L.; Giovannelli, A.; Frediani, P.; Frediani, M. Characterization of bio-oil and bio-char produced by lowtemperature microwave-assisted pyrolysis of olive pruning residue using various absorbers. Waste Manag. Res. 2020, 38, 213-225. [CrossRef] [PubMed]

101. Liu, Y.; Ran, C.; Siddiqui, A.R.; Mao, X.; Kang, Q.; Fu, J.; Deng, Z.; Song, Y.; Jiang, Z.; Zhang, T.; et al. Pyrolysis of textile dyeing sludge in fluidized bed and microwave-assisted auger reactor: Comparison and characterization of pyrolysis products. J. Hazard. Mater. 2018, 359, 454-464. [CrossRef] [PubMed]

102. Salema, A.A.; Ani, F.N. Microwave-assisted pyrolysis of oil palm shell biomass using an overhead stirrer. J. Anal. Appl. Pyrolysis 2012, 96, 162-172. [CrossRef]

103. Beneroso, D.; Monti, T.; Kostas, E.T.; Robinson, J. Microwave pyrolysis of biomass for bio-oil production: Scalable processing concepts. Chem. Eng. J. 2017, 316, 481-498. [CrossRef]

104. Salema, A.A.; Afzal, M.T.; Bennamoun, L. Pyrolysis of corn stalk biomass briquettes in a scaled-up microwave technology. Bioresour. Technol. 2017, 233, 353-362. [CrossRef] [PubMed]

105. Tyrebirth. Available online: https://www.tyrebirth.com/it/ (accessed on 2 March 2021).

106. Wang, Y.; Zeng, Z.; Tian, X.; Dai, L.; Jiang, L.; Zhang, S.; Wu, Q.; Wen, P.; Fu, G.; Liu, Y.; et al. Production of bio-oil from agricultural waste by using a continuous fast microwave pyrolysis system. Bioresour. Technol. 2018, 269, 162-168. [CrossRef]

107. Hussain, K.; Bashir, N.; Hussain, Z.; Sulaiman, S.A. Cement catalyzed conversion of biomass into upgraded bio-oil through microwave metal interaction pyrolysis in aluminum coil reactor. J. Anal. Appl. Pyrolysis 2018, 129, 37-42. [CrossRef]

108. Bashir, N.; Hussain, K.; Hussain, Z.; Naz, M.Y.; Ibrahim, K.A.; Abdel-Salam, N.M. Effect of metal coil on product distribution of highly upgraded bio-oil produced by microwave-metal interaction pyrolysis of biomass. Chem. Eng. Process. Process Intensif. 2018, 130, 140-147. [CrossRef]

109. Halim, S.A.; Swithenbank, J. Characterisation of Malaysian wood pellets and rubberwood using slow pyrolysis and microwave technology. J. Anal. Appl. Pyrolysis 2016, 122, 64-75. [CrossRef] 
110. Nhuchhen, D.R.; Afzal, M.T.; Dreise, T.; Salema, A.A. Characteristics of biochar and bio-oil produced from wood pellets pyrolysis using a bench scale fixed bed, microwave reactor. Biomass Bioenergy 2018, 119, 293-303. [CrossRef]

111. Abas, F.Z.; Ani, F.N.; Zakaria, Z.A. Microwave-assisted production of optimized pyrolysis liquid oil from oil palm fiber. J. Clean. Prod. 2018, 182, 404-413. [CrossRef]

112. Mushtaq, F.; Abdullah, T.A.T.; Mat, R.; Ani, F.N. Optimization and characterization of bio-oil produced by microwave assisted pyrolysis of oil palm shell waste biomass with microwave absorber. Bioresour. Technol. 2015, 190, 442-450. [CrossRef]

113. Bartoli, M.; Rosi, L.; Giovannelli, A.; Frediani, P.; Frediani, M. Production of bio-oils and bio-char from Arundo donax through microwave assisted pyrolysis in a multimode batch reactor. J. Anal. Appl. Pyrolysis 2016, 122, 479-489. [CrossRef]

114. Dong, Q.; Li, H.; Niu, M.; Luo, C.; Zhang, J.; Qi, B.; Li, X.; Zhong, W. Microwave pyrolysis of moso bamboo for syngas production and bio-oil upgrading over bamboo-based biochar catalyst. Bioresour. Technol. 2018, 266, 284-290. [CrossRef]

115. Dong, Q.; Li, X.; Wang, Z.; Bi, Y.; Yang, R.; Zhang, J.; Luo, H.; Niu, M.; Qi, B.; Lu, C. Effect of iron(III) ion on moso bamboo pyrolysis under microwave irradiation. Bioresour. Technol. 2017, 243, 755-759. [CrossRef]

116. Dong, Q.; Niu, M.; Bi, D.; Liu, W.; Gu, X.; Lu, C. Microwave-assisted catalytic pyrolysis of moso bamboo for high syngas production. Bioresour. Technol. 2018, 256, 145-151. [CrossRef]

117. Tarves, P.C.; Serapiglia, M.J.; Mullen, C.A.; Boateng, A.A.; Volk, T.A. Effects of hot water extraction pretreatment on pyrolysis of shrub willow. Biomass Bioenergy 2017, 107, 299-304. [CrossRef]

118. Feng, Y.; Li, G.; Li, X.; Zhu, N.; Xiao, B.; Li, J.; Wang, Y. Enhancement of biomass conversion in catalytic fast pyrolysis by microwave-assisted formic acid pretreatment. Bioresour. Technol. 2016, 214, 520-527. [CrossRef]

119. Grycova, B.; Pryszcz, A.; Lestinsky, P.; Chamradova, K. Influence of potassium hydroxide and method of carbonization treatment in garden and corn waste microwave pyrolysis. Biomass Bioenergy 2018, 118, 40-45. [CrossRef]

120. Choi, J.; Nam, H.; Capareda, S.C. Effect of metal salts impregnation and microwave-assisted solvent pretreatment on selectivity of levoglucosenone and levoglucosan from vacuum pyrolysis of ashe juniper waste. J. Environ. Chem. Eng. 2019, 7, 102796. [CrossRef]

121. Wan, Y.; Chen, P.; Zhang, B.; Yang, C.; Liu, Y.; Lin, X.; Ruan, R. Microwave-assisted pyrolysis of biomass: Catalysts to improve product selectivity. J. Anal. Appl. Pyrolysis 2009, 86, 161-167. [CrossRef]

122. Mohamed, B.A.; Ellis, N.; Kim, C.S.; Bi, X. Microwave-assisted catalytic biomass pyrolysis: Effects of catalyst mixtures. Appl. Catal. B Environ. 2019, 253, 226-234. [CrossRef]

123. Mohamed, B.A.; Kim, C.S.; Ellis, N.; Bi, X. Microwave-assisted catalytic pyrolysis of switchgrass for improving bio-oil and biochar properties. Bioresour. Technol. 2016, 201, 121-132. [CrossRef]

124. Shang, H.; Lu, R.-R.; Shang, L.; Zhang, W.-H. Effect of additives on the microwave-assisted pyrolysis of sawdust. Fuel Process. Technol. 2015, 131, 167-174. [CrossRef]

125. Chitnis, G.K.; Herbst, J.A. Cracking Catalysts Containing Phosphate Treated Zeolites, and Method of Preparing the Same. U.S. Patent No 5,110,776, 5 May 1992.

126. Emig, G.; Hofmann, H. Action of zirconium phosphate as a catalyst for the oxydehydrogenation of ethylbenzene to styrene. J. Catal. 1983, 84, 15-26. [CrossRef]

127. Swift, H.E.; Stanulonis, J.J.; Reynolds, E.H. Alumina-aluminum phosphate-silica-zeolite catalyst. U.S. Patent No. 4,228, 036, 14 October 1980.

128. Vitolo, S.; Seggiani, M.; Frediani, P.; Ambrosini, G.; Politi, L. Catalytic upgrading of pyrolytic oils to fuel over different zeolites. Fuel 1999, 78, 1147-1159. [CrossRef]

129. Zhang, B.; Zhong, Z.; Xie, Q.; Liu, S.; Ruan, R. Two-step fast microwave-assisted pyrolysis of biomass for bio-oil production using microwave absorbent and HZSM-5 catalyst. J. Environ. Sci. 2016, 45, 240-247. [CrossRef]

130. Zhang, B.; Zhong, Z.; Li, T.; Xue, Z.; Wang, X.; Ruan, R. Biofuel production from distillers dried grains with solubles (DDGS) co-fed with waste agricultural plastic mulching films via microwave-assisted catalytic fast pyrolysis using microwave absorbent and hierarchical ZSM-5/MCM-41 catalyst. J. Anal. Appl. Pyrolysis 2018, 130, 1-7. [CrossRef]

131. Zhang, B.; Zhong, Z.; Chen, P.; Ruan, R. Microwave-assisted catalytic fast co-pyrolysis of Ageratina adenophora and kerogen with CaO and ZSM-5. J. Anal. Appl. Pyrolysis 2017, 127, 246-257. [CrossRef]

132. Zhang, B.; Zhong, Z.; Chen, P.; Ruan, R. Microwave-assisted catalytic fast pyrolysis of biomass for bio-oil production using chemical vapor deposition modified HZSM-5 catalyst. Bioresour. Technol. 2015, 197, 79-84. [CrossRef]

133. Zhang, B.; Zhang, J.; Zhong, Z.; Zhang, Y.; Song, M.; Wang, X.; Ding, K.; Ruan, R. Conversion of poultry litter into bio-oil by microwave-assisted catalytic fast pyrolysis using microwave absorbent and hierarchical ZSM-5/MCM-41 catalyst. J. Anal. Appl. Pyrolysis 2018, 130, 233-240. [CrossRef]

134. Zhang, B.; Tan, G.; Zhong, Z.; Ruan, R. Microwave-assisted catalytic fast pyrolysis of spent edible mushroom substrate for bio-oil production using surface modified zeolite catalyst. J. Anal. Appl. Pyrolysis 2017, 123, 92-98. [CrossRef]

135. Wang, J.; Zhong, Z.; Song, Z.; Ding, K.; Deng, A. Modification and regeneration of HZSM-5 catalyst in microwave assisted catalytic fast pyrolysis of mushroom waste. Energy Convers. Manag. 2016, 123, 29-34. [CrossRef]

136. Sun, J.; Wang, K.; Song, Z.; Lv, Y.; Chen, S. Enhancement of bio-oil quality: Metal-induced microwave-assisted pyrolysis coupled with ex-situ catalytic upgrading over HZSM-5. J. Anal. Appl. Pyrolysis 2019, 137, 276-284. [CrossRef]

137. Liu, S.; Xie, Q.; Zhang, B.; Cheng, Y.; Liu, Y.; Chen, P.; Ruan, R. Fast microwave-assisted catalytic co-pyrolysis of corn stover and scum for bio-oil production with CaO and HZSM-5 as the catalyst. Bioresour. Technol. 2016, 204, 164-170. [CrossRef] [PubMed] 
138. Dai, L.; Fan, L.; Duan, D.; Ruan, R.; Wang, Y.; Liu, Y.; Zhou, Y.; Yu, Z.; Liu, Y.; Jiang, L. Production of hydrocarbon-rich bio-oil from soapstock via fast microwave-assisted catalytic pyrolysis. J. Anal. Appl. Pyrolysis 2017, 125, 356-362. [CrossRef]

139. Zhang, B.; Zhong, Z.; Li, T.; Xue, Z.; Ruan, R. Bio-oil production from sequential two-step microwave-assisted catalytic fast pyrolysis of water hyacinth using Ce-doped $\gamma$-Al2O3/ZrO2 composite mesoporous catalyst. J. Anal. Appl. Pyrolysis 2018, 132, 143-150. [CrossRef]

140. Mortensen, P.M.; Grunwaldt, J.-D.; Jensen, P.A.; Knudsen, K.; Jensen, A.D. A review of catalytic upgrading of bio-oil to engine fuels. Appl. Catal. A Gen. 2011, 407, 1-19. [CrossRef]

141. Gooty, A.T.; Li, D.; Briens, C.; Berruti, F. Fractional condensation of bio-oil vapors produced from birch bark pyrolysis. Sep. Purif. Technol. 2014, 124, 81-88. [CrossRef]

142. Westerhof, R.J.; Brilman, D.W.F.; Garcia-Perez, M.; Wang, Z.; Oudenhoven, S.R.; van Swaaij, W.P.; Kersten, S.R. Fractional condensation of biomass pyrolysis vapors. Energy Fuels 2011, 25, 1817-1829. [CrossRef]

143. Dai, L.; Wang, Y.; Liu, Y.; Ruan, R.; Yu, Z.; Jiang, L. Comparative study on characteristics of the bio-oil from microwave-assisted pyrolysis of lignocellulose and triacylglycerol. Sci. Total Environ. 2019, 659, 95-100. [CrossRef]

144. Omidghane, M.; Bartoli, M.; Asomaning, J.; Xia, L.; Chae, M.; Bressler, D.C. Pyrolysis of fatty acids derived from hydrolysis of brown grease with biosolids. Env. Sci. Pollut. Res. 2020. [CrossRef]

145. Wang, Y.; Dai, L.; Shan, S.; Zeng, Q.; Fan, L.; Liu, Y.; Ruan, R.; Zhao, Y.; Zhou, Y. Effect of unsaturation degree on microwaveassisted pyrolysis of fatty acid salts. J. Anal. Appl. Pyrolysis 2016, 120, 247-251. [CrossRef]

146. Ng, J.-H.; Leong, S.K.; Lam, S.S.; Ani, F.N.; Chong, C.T. Microwave-assisted and carbonaceous catalytic pyrolysis of crude glycerol from biodiesel waste for energy production. Energy Convers. Manag. 2017, 143, 399-409. [CrossRef]

147. Omar, R.; Robinson, J.P. Conventional and microwave-assisted pyrolysis of rapeseed oil for bio-fuel production. J. Anal. Appl. Pyrolysis 2014, 105, 131-142. [CrossRef]

148. Du, Z.; Li, Y.; Wang, X.; Wan, Y.; Chen, Q.; Wang, C.; Lin, X.; Liu, Y.; Chen, P.; Ruan, R. Microwave-assisted pyrolysis of microalgae for biofuel production. Bioresour. Technol. 2011, 102, 4890-4896. [CrossRef]

149. Zhang, R.; Li, L.; Tong, D.; Hu, C. Microwave-enhanced pyrolysis of natural algae from water blooms. Bioresour. Technol. 2016, 212, 311-317. [CrossRef]

150. Hu, Z.; Ma, X.; Chen, C. A study on experimental characteristic of microwave-assisted pyrolysis of microalgae. Bioresour. Technol. 2012, 107, 487-493. [CrossRef]

151. Budarin, V.L.; Zhao, Y.; Gronnow, M.J.; Shuttleworth, P.S.; Breeden, S.W.; Macquarrie, D.J.; Clark, J.H. Microwave-mediated pyrolysis of macro-algae. Green Chem. 2011, 13, 2330-2333. [CrossRef]

152. Xie, Q.; Addy, M.; Liu, S.; Zhang, B.; Cheng, Y.; Wan, Y.; Li, Y.; Liu, Y.; Lin, X.; Chen, P.; et al. Fast microwave-assisted catalytic co-pyrolysis of microalgae and scum for bio-oil production. Fuel 2015, 160, 577-582. [CrossRef]

153. Dai, M.; Xu, H.; Yu, Z.; Fang, S.; Chen, L.; Gu, W.; Ma, X. Microwave-assisted fast co-pyrolysis behaviors and products between microalgae and polyvinyl chloride. Appl. Therm. Eng. 2018, 136, 9-15. [CrossRef]

154. Duan, D.; Ruan, R.; Lei, H.; Liu, Y.; Wang, Y.; Zhang, Y.; Zhao, Y.; Dai, L.; Wu, Q.; Zhang, S. Microwave-assisted co-pyrolysis of pretreated lignin and soapstock for upgrading liquid oil: Effect of pretreatment parameters on pyrolysis behavior. Bioresour. Technol. 2018, 258, 98-104. [CrossRef]

155. Wang, Y.; Wu, Q.; Duan, D.; Ruan, R.; Liu, Y.; Dai, L.; Zhou, Y.; Zhao, Y.; Zhang, S.; Zeng, Z. Ex-situ catalytic upgrading of vapors from fast microwave-assisted co-pyrolysis of Chromolaena odorata and soybean soapstock. Bioresour. Technol. 2018, 261, 306-312. [CrossRef]

156. Wang, Y.; Tian, X.; Zeng, Z.; Dai, L.; Zhang, S.; Jiang, L.; Wu, Q.; Yang, X.; Liu, Y.; Zhang, B.; et al. Catalytic co-pyrolysis of Alternanthera philoxeroides and peanut soapstock via a new continuous fast microwave pyrolysis system. Waste Manag. 2019, 88, 102-109. [CrossRef]

157. Borges, F.C.; Xie, Q.; Min, M.; Muniz, L.A.R.; Farenzena, M.; Trierweiler, J.O.; Chen, P.; Ruan, R. Fast microwave-assisted pyrolysis of microalgae using microwave absorbent and HZSM-5 catalyst. Bioresour. Technol. 2014, 166, 518-526. [CrossRef]

158. Kadlimatti, H.M.; Raj Mohan, B.; Saidutta, M.B. Bio-oil from microwave assisted pyrolysis of food waste-optimization using response surface methodology. Biomass Bioenergy 2019, 123, 25-33. [CrossRef]

159. Chen, W.; Shi, S.; Zhang, J.; Chen, M.; Zhou, X. Co-pyrolysis of waste newspaper with high-density polyethylene: Synergistic effect and oil characterization. Energy Convers. Manag. 2016, 112, 41-48. [CrossRef]

160. Zhao, Y.; Wang, Y.; Duan, D.; Ruan, R.; Fan, L.; Zhou, Y.; Dai, L.; Lv, J.; Liu, Y. Fast microwave-assisted ex-catalytic co-pyrolysis of bamboo and polypropylene for bio-oil production. Bioresour. Technol. 2018, 249, 69-75. [CrossRef]

161. Suriapparao, D.V.; Boruah, B.; Raja, D.; Vinu, R. Microwave assisted co-pyrolysis of biomasses with polypropylene and polystyrene for high quality bio-oil production. Fuel Process. Technol. 2018, 175, 64-75. [CrossRef] 